\title{
Analysis of biogenic amines and inorganic elements in Cheonggukjang
}

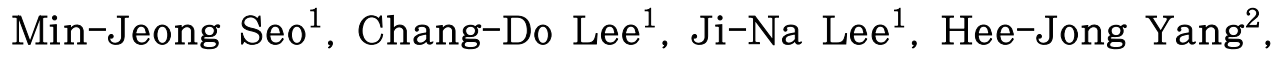 \\ Do-Youn Jeong ${ }^{2}$, Gae-Ho Lee ${ }^{1 *}$ \\ ${ }^{1}$ Korea Research Institute of Analytical Technology (KRIAT), Daejeon 34024, Korea \\ ${ }^{2}$ Microbioal Institute for Fermentation Industry (MIFI), Sunchang 56048, Korea
}

\section{청국장 중 바이오제닉 아민 및 무기원소함량 분석}

\author{
서민정 ${ }^{1} \cdot$ 이창도 $^{1} \cdot$ 이지나 ${ }^{1} \cdot$ 양희종 ${ }^{2} \cdot$ 정도연 $^{2} \cdot$ 이계호 $^{1 *}$ \\ ${ }^{1}$ (주) 한국분석기술연구소, ${ }^{2}$ (재) 발효미생물산업진흥원
}

\begin{abstract}
The quantitative analyses of biogenic amines (BAs) in fermented food is one of the critical issues in food safety. Thirty-seven samples were analyzed in order to determine the BA content in Cheonggukjang. Additionally inorganic elements in 6 samples were analyzed using inductively coupled plasma atomic emission spectroscopy and inductively coupled plasma mass spectrometry. The BA content was analyzed using high-performance liquid-chromatography (HPLC) after derivatization of the samples by densyl chloride. Biogenic amines, namely, tryptamine (TRP), 2-phenylethylamine (PHE), putrescine (PUT), cadaverine (CAD), histamine (HIS), tyramine (TYR) spermidine (SPD), and spermine (SPM) were detected by monitoring the absorbance from the samples at $254 \mathrm{~nm}$ using the UV-vis detector attached to the HPLC system. The chromatograms were also verified for linearity and accuracy. The results showed that all the correlation coefficients $\left(R^{2}\right)$ were over 0.99 , while the recovery was $89.7 \%-103.4 \%$. The average BA contents in Cheonggukjang were as follows: TRP $43.8 \mathrm{mg} / \mathrm{kg}$, PHE $11.8 \mathrm{mg} / \mathrm{kg}$, PUT $10.6 \mathrm{mg} / \mathrm{kg}$, CAD 10.3 $\mathrm{mg} / \mathrm{kg}$, HIS $3.8 \mathrm{mg} / \mathrm{kg}$, TYR $113.7 \mathrm{mg} / \mathrm{kg}$, SPD $37.6 \mathrm{mg} / \mathrm{kg}$, SPM $11.5 \mathrm{mg} / \mathrm{kg}$. The average contents of inorganic elements in Cheonggukjang were as follows Na 0.93\%, K 0.55\%, Ca 0.14\%, P 0.30\%, Mg 0.11\%, $\mathrm{S} \mathrm{0.17 \% ,} \mathrm{Fe}$ $29.6 \mathrm{mg} / \mathrm{kg}$, Mn $13.4 \mathrm{mg} / \mathrm{kg}$, Zn $17.6 \mathrm{mg} / \mathrm{kg}$, Cu $3.44 \mathrm{mg} / \mathrm{kg}$, Sr $3.21 \mathrm{mg} / \mathrm{kg}$, Mo $1.40 \mathrm{mg} / \mathrm{kg}$, Ba $2.12 \mathrm{mg} / \mathrm{kg}$, Se $0.071 \mathrm{mg} / \mathrm{kg}$, Cd $0.014 \mathrm{mg} / \mathrm{kg}$, As $0.011 \mathrm{mg} / \mathrm{kg}$.
\end{abstract}

Key words : Cheonggukjang, biogenic amines, inorganic elements

\section{서 론}

콩은 비타민, 무기질 등이 다량 함유되어 있어 영양학적 가치가 높은 식품으로(1) 우리나라를 비롯한 동양권에서 식생활의 영양공급원으로 이용되고 있다(2). 이 중 청국장 은 콩을 원료로한 우리나라의 전통적인 발효식품으로 된장 이나 고추장보다 단백질과 지방함량이 높은 고영양식품이

*Corresponding author. E-mail : ghlee@cnu.ac.kr Phone : 82-42-823-7241, Fax : 82-42-823-6263

Received 13 September 2018; Revised 21 November 2018; Accepted 26 November 2018.

Copyright (c) The Korean Society of Food Preservation. All rights reserved.
다(3). 또한 곡류 단백질에서 부족하기 쉬운 필수아미노산, 지방산, 유기산, 미네랄 및 비타민류 등의 영양소를 보충해 줌으로서 영양학적으로 중요한 기능식품이다.

청국장 뿐만 아니라 식품 중에는 여러 금속 물질이 함유 되어 있는데, 이들 중 중금속은 크게 필수중금속과 유해중 금속으로 구분된다. 생체 내의 생리기능을 유지하기 위해 필요로 하는 필수중금속에는 아연, 철, 구리, 코발트 등이 있으며, 생체 내에 해로운 영향은 미치는 유해중금속으로 는 수은, 납, 카드뮴 등이 있다(4). 발효식품의 다른 종류인 고추장과 된장의 경우 개별적으로 유해중금속 함량분석이 이루어지고 있지만, 청국장의 경우 필수 및 유해 중금속의 연구가 미비한 것이 사실이다. 또한 전통식품의 경우 대량 으로 생산되어 유통되는 경로 외에 전통시장이나 영세한 
식품 가공업체에서 생산되는 경우도 많아(5), 원재료에서 야기되는 오염 뿐만 아니라 저장, 제조, 가공 및 포장 단계 중 발생될 수 있는 오염에 대해서도 생각해볼 필요가 있다.

청국장의 숙성은 미생물을 이용한 발효과정을 거치게 되는데 Bacillus subtilis, Bacillus licheniformis 및 Bacillus megaterium과 같은 Bacillus속의 균주를 단독(6-10) 또는 두 균주를 혼합 $(10,11)$ 하는 경우가 대부분이다. 이러한 발 효과정 중 소량의 유해물질들이 생성될 수 있는데, 이중 하나가 biogenic amines(BAs)이다. BAs류는 지방족 (putrescine, cadaverine, spermine,spermidine), 방향족(tyramine, phenylethylamine), 헤테로고리구조(histamine, tryptamine) 를 가진 형태로 되어 있으며(12), 주로 동·식물에서 아미노 산의 탈 탄산작용 및 알데히드와 케톤의 아미노화와 아미노 기 전이반응에 의해 생성되는 저분자 화합물이다(13). 이러 한 $\mathrm{BAs}$ 류는 여러 장류 식품으로부터 지속적으로 검출되고 있으며 인체에 신경계이상, 혈관계이상 등을 유발시키는 것으로 알려져 있다. BAs 중 하나인 HIS은 여러 차례 연구 를 통해 식중독 발생의 원인이 되며 일부 $\mathrm{BAs}$ 은 $\mathrm{N}$-nitrosamine과 같은 발암물질로 전환될 수 있는 것으로 밝혀졌다(13).

고단백질을 함유한 콩의 발효과정을 통해 만들어지는 청국장의 경우 $\mathrm{BAs}$ 위험에 쉽게 노출될 수 있어 지속적인 모니터링 및 관리가 필요한 것으로 보인다.

이에 본 연구에서는 시중에 판매되는 청국장(마트, 전통 시장)의 발효과정 중 생성되는 BAs 및 무기원소의 함량을 모니터링하였다.

\section{재료 및 방법}

\section{실험재료}

대전 및 순창지역에서 청국장을 수거하여 실험을 진행하 였다. 수거된 37종은 전국으로 유통되는 청국장으로 2016 년 11월부터 2017년 6월까지 이루어졌으며, 마트(26건)와 시장(11건)에서 구매하였다. 수거된 시료는 sampling 전까 지 냉동고(GC-124HGFP, LG, Changwon, Korea) $-20^{\circ} \mathrm{C}$ 에 보관하였으며, 실험시에는 상온으로 유지시킨 후 분쇄기 (HMF-3000, Hanil, Wonju, Korea) 를 이용하여 균질화하였 다. 이 중 6 건에 대하여는 무기원소 실험도 함께 진행되었다.

\section{시약 및 초자}

본 연구에 사용한 BAs의 표준품으로 putrescine(PUT), cadaverine(CAD), spermidine(SPD), spermine(SPM), tryptamine (TRY), histamine(HIS), tyramine(TYR), $\beta$-phenylethylamine $(\mathrm{PHE})$ 은 각각 $1,000 \mathrm{mg} / \mathrm{L}(0.1 \mathrm{~N} \mathrm{HCl})$ 로 제조하여 사용하였 다. 유도체 시약 dansyl chloride(Sigma-Aldrich Co., St. Louis, MO, USA)와 L-proline(Sigma-Aldrich Co.)은 각각
$10 \%, 1 \%$ 로 제조하여 사용하였다. 포화탄산나트륨용액은 $\mathrm{Na}_{2} \mathrm{CO}_{3}$ (sodium carbonate anhydrous, Daejung Chemicals, Siheung, Korea) $46 \mathrm{~g}$ 을 증류수 $100 \mathrm{~mL}$ 에 용해 사용하였다. 추출용 시약으로는 반도체급의 $\mathrm{HCl}$ (Dongwoo Fine-Chem, Iksan, Korea)을 희석하여 사용하였고, 기기분석 용매로는 HPLC 등급의 acetonitrile(J.T Baker, Center Valley, PA, USA)를 사용하였다. 무기원소 전처리에 사용된 시약은 반 도체급의 $\mathrm{HNO}_{3}$ 과 $\mathrm{H}_{2} \mathrm{O}_{2}$ (Dong Woo Fine- Chem)이며, 사용 된 물은 초순수장치(Milli-Q, Millipore, Billerica, MA, USA) 로 $18 \mathrm{M}$ 이상 수준으로 정제된 초순수를 사용하였다. 무기 원소 표준용액은 NIST(National Institute of Standards and Technology, Gaithersburg, PA, USA) 표준용액을 $2 \% \mathrm{HNO}_{3}$ 으로 제조하여 사용하였다.

\section{바이오제닉아민 분석}

BAs의 분석은 Garcia-Garcia 등(14)의 방법과 일본위생 시험법의 불휘발성 부패아민 분석법(15)을 변형하여 사용 하였다. 시료 약 $5 \mathrm{~g}$ 을 취하여 $0.1 \mathrm{~N} \mathrm{HCl} 25 \mathrm{~mL}$ 를 가한 후 균질화하여 $4,000 \mathrm{G}, 4^{\circ} \mathrm{C}, 15 \mathrm{~min}$ 의 조건으로 원심분리 (Combi 514R, HANIL, Wonju, Korea)하였다. 원심분리 후 여과하여 취하는 조작을 2 회 반복하여 상층액을 합치고 $0.1 \mathrm{~N} \mathrm{HCl}$ 을 가해 $50 \mathrm{~mL}$ 로 한 것을 추출용액으로 하였다. 표준용액 및 추출용액 각각 $1 \mathrm{~mL}$ 를 마개 달린 유리시험관 에 취한 후 포화탄산나트륨용액 $0.5 \mathrm{~mL}$ 와 유도체화시약인 $1 \%$ dansyl chloride $0.8 \mathrm{~mL}$ 을 가하여 혼합한 후 마개를 닫아 $45^{\circ} \mathrm{C}$ 에서 1 시간 유도체화하였다. 유도체화 시킨 용액에 $10 \%$ proline 용액 $0.5 \mathrm{~mL}$ 및 에테르 $5 \mathrm{~mL}$ 을 가하여 10 분간 vortex mixer(099A VB4, Glas-Col, Terre Haute, IN, USA)로 진탕하고 상층액을 취하여 질소농축기(HV-300, INTERFACE, Seoul, Korea)에 농축하였다. 농축한 시료에 acetonitrile 1 $\mathrm{mL}$ 를 가하여 $0.45 \mu \mathrm{m}$ 로 여과한 것을 시험용액으로 하였다. 분석은 HPLC(Prominace series, Shimadzu, Kyoto, Japan)로 하였으며, column은 Agilent polaris $3\left(\mathrm{C}_{18}-\mathrm{A} 150 \times 4.6 \mathrm{~mm}\right.$, $\left.3 \mu \mathrm{m}, 40^{\circ} \mathrm{C}\right)$ 를 이용하였다. 기기분석 시 용매는 gradient elution조건(A:ACN, B:water, 0 min $55 \%$ B/10 $\min 55 \%$ B, $15 \min 65 \% \mathrm{~B} / 20 \min 80 \% \mathrm{~B}, 25 \min 80 \% \mathrm{~B} / 30 \min 90 \%$ $\mathrm{B}, 33 \min 90 \% \mathrm{~B} / 35 \min 55 \% \mathrm{~B}, 40 \min 55 \% \mathrm{~B})$ 으로 $\mathrm{UV}-254 \mathrm{~nm}$ 에서 분석을 진행하였다.

\section{무기원소 분석}

시료전처리는 식품공전(식약처 고시 「식품의 기준 및 규격」)의 마이크로웨이브법(16)을 사용하였다. 균질화된 시료 약 $0.2 \mathrm{~g}$ 을 microwave(Xpress, CEM, Matthews, NC, USA) vessel에 취하고 질산과 과산화수소를 첨가하여 $1,200 \mathrm{~W}$ 로 $15 \mathrm{~min}$ 동안 $180^{\circ} \mathrm{C}$ 까지 온도를 높인 후 $20 \mathrm{~min}$ 동 안 $180^{\circ} \mathrm{C}$ 로 유지시켜 분해하였다. $30 \mathrm{~min}$ 동안 cooling 후 초순수를 이용하여 $20 \mathrm{~g}$ 으로 최종 시험액이 되도록 하였다. 
기기분석은 ICP-AES(Arcos, Spectro, Kleve, Germany)와 ICP-MS(icapQ, Thermo, Waltham, MA, USA)를 이용하였 다. 함량이 높은 $\mathrm{Na}, \mathrm{K}, \mathrm{Mg}, \mathrm{P}, \mathrm{Ca}, \mathrm{S}$ 는 ICP-AES로 미량성분 인 $\mathrm{Fe}, \mathrm{Mn}, \mathrm{Zn}, \mathrm{Cu}, \mathrm{Sr}, \mathrm{Mo}, \mathrm{Ba}, \mathrm{Se}$ 은 ICP-MS로 분석하였다.

\section{측정불확도}

불확도는 GUM(Guide to the Expression of the Uncertainty in Measurement) 및 국제표준화기구(ISO)의 측정불확도 표 현 지침서(Guide to the Expression of Uncertainty in Measurement)(17)에 따라 산출되었다. 불확도 추정절차는 모델식(계산식 등)을 설정한 후 불확도 요인을 산출하며, 요인별 표준불확도(A형, B형)와 자유도를 계산한 후 감도 계수 또는 불확도 요인의 측정값으로 나누어 각 요인별 상대표준불확도를 구하였다. 여러 개의 불확도 요인에 대 한 표준불확도를 구하여 합성된 값의 합성표준불확도를 구한 후 포함인자 $k$ 를 구하기 위해서 합성표준불확도의 유효자유도를 추정하였다. 확장불확도는 합성표준불확도

$$
\mathrm{Cs}=\mathrm{Cso} \times \frac{\mathrm{V}}{\mathrm{M}}
$$

Cs : concentration of sample $(\mathrm{mg} / \mathrm{kg})$

Cso : calculation of concentration in sample $(\mathrm{mg} / \mathrm{L})$

$\mathrm{V}$ : final volume of sample $(\mathrm{mL})$

$\mathrm{M}$ : weight of sample(g)

$$
\mathrm{Cso}=\frac{\text { Iso-b }}{\mathrm{a}}
$$

Cso : concentration of sample $(\mathrm{mg} / \mathrm{kg})$

Iso : intensity of sample

a : slope of the calibration curve

b : intercept of calibration curve
에 포함인자 $k$ 를 곱하여 산출하였다.

\section{결과 및 고찰}

\section{회수율 및 표준인증물질 실험}

인증표준물질(Certified reference material, CRM)인 canned fish(T27176QC, FAPAS)를 이용해서 회수율을 확인 한 결과 histamin은 인증값에 대해 $97.8 \%$ 값을 얻었으며, 자세한 결과는 Table 1 과 같다. 직선성은 $10-100 \mathrm{mg} / \mathrm{L}$ 의 범위에서 검량선을 확인하였다. 그 결과 8 종 모두 $\mathrm{R}^{2}$ 는 0.998 이상의 직선성을 나타내었다. BAs 8종의 회수율실험 은 혼합표준용액을 각각 $2.0 \mathrm{mg} / \mathrm{kg}, 4.0 \mathrm{mg} / \mathrm{kg}$ 농도수준으 로 첨가하여 $80-110 \%$ 의 결과를 얻을 수 있었으며, 자세한 결과는 Table 2 와 같다.

무기원소 또한 인증표준물질의 회수율을 확인하여 분석 법을 검증하였다. 한국표준과학연구원(Korea Research Institute of Standards and Science, KRISS)의 쌀 분말과 미국

Table 2. Results of spiking test for biogenic amines in Cheonggukjang

\begin{tabular}{cccc}
\hline \multirow{2}{*}{ Analyte $^{1)}$} & \multicolumn{2}{c}{ Recovery (\%) } & \multirow{2}{*}{$\mathrm{R}^{2}$} \\
\cline { 2 - 3 } & $2 \mathrm{mg} / \mathrm{kg}$ & $4 \mathrm{mg} / \mathrm{kg}$ & 0.9986 \\
\hline TRP & $106.9 \pm 4.9^{2)}$ & $93.7 \pm 5.3$ & 0.9998 \\
2-PHE & $97.4 \pm 7.1$ & $88.8 \pm 5.6$ & 0.9995 \\
PUT & $98.2 \pm 5.9$ & $104.8 \pm 6.7$ & 0.9999 \\
HIS & $88.2 \pm 1.4$ & $86.6 \pm 4.7$ & 0.9999 \\
TYR & $97.3 \pm 6.9$ & $91.5 \pm 2.7$ & 0.9999 \\
SPD & $104.0 \pm 6.5$ & $96.6 \pm 2.8$ & 0.9998 \\
SPM & $94.9 \pm 6.0$ & $96.9 \pm 5.1$ & \\
\hline
\end{tabular}

${ }^{11} \mathrm{TRP}$, tryptamine; PHE, 2-phenylethylamine; PUT, putrescine; CAD, cadaverine; HIS, histamine; TYR, tyramine; SPD, spermidine; SPM, spermine.

${ }^{2)}$ All the data were expressed as mean \pm SD $(n=3)$.

Table 1. The measurement of certified reference matrial (CRM)

\begin{tabular}{ccccc}
\hline CRM & Analyte & $\begin{array}{c}\text { Certified value } \\
(\mathrm{mg} / \mathrm{kg})\end{array}$ & $\begin{array}{c}\text { Mean of measurement } \\
(\mathrm{mg} / \mathrm{kg})\end{array}$ & $\begin{array}{c}\text { Recovery } \\
(\%)\end{array}$ \\
\hline $\begin{array}{c}\text { Canned fish } \\
(\mathrm{T} 27176 \mathrm{Q})\end{array}$ & Histamine & 216 & $220.7 \pm 17.2^{2)}$ & 97.8 \\
\hline $\begin{array}{c}\text { Rice flour } \\
(108-01-003)\end{array}$ & $\mathrm{Cd}$ & 1.446 & $1.248 \pm 0.025^{4)}$ & 86.3 \\
\hline $\begin{array}{c}\text { Tomato leaves) } \\
(1573 \mathrm{a})\end{array}$ & $\mathrm{Pb}$ & 0.123 & $0.131 \pm 0.002$ & 107.1 \\
\hline $\begin{array}{c}\text { Rice flour } \\
(1568 \mathrm{a})\end{array}$ & $\mathrm{Cd}$ & 1.52 & $1.59 \pm 0.03$ & 104.8 \\
\hline
\end{tabular}

\footnotetext{
${ }^{1)}$ Food and Environment Research Agency (FAPAS, UK).

${ }^{2)}$ The data were expressed as mean $\pm \mathrm{SD}(\mathrm{n}=5)$.

${ }^{3}$ Korea Research Institute of Standards and Science (KRISS, Korea).

${ }^{4)}$ The data were expressed as mean $\pm \mathrm{SD}(\mathrm{n}=3)$.

${ }^{5}$ National Institute of Standards and Technology (NIST, USA)
} 
Table 3. Contents of biogenic amines in Cheonggukjang

\begin{tabular}{|c|c|c|c|c|c|c|c|c|}
\hline \multirow{2}{*}{ No. ${ }^{1)}$} & \multicolumn{8}{|c|}{ Biogenic amines concentration $(\mathrm{mg} / \mathrm{kg})$} \\
\hline & TRP & PHE & PUT & $\mathrm{CAD}$ & HIS & TYR & SPD & SPM \\
\hline CP-01 & $35.4 \pm 2.3^{2)}$ & $5.4 \pm 0.8$ & $4.2 \pm 0.2$ & $3.7 \pm 0.2$ & $4.1 \pm 0.1$ & $53.7 \pm 20.1$ & $24.1 \pm 3.0$ & $7.8 \pm 0.3$ \\
\hline CP-02 & $16.9 \pm 2.0$ & $2.7 \pm 0.5$ & $4.5 \pm 0.3$ & $3.1 \pm 0.4$ & $3.5 \pm 0.2$ & $17.2 \pm 2.4$ & $13.8 \pm 1.5$ & $7.5 \pm 0.4$ \\
\hline CP-03 & $26.4 \pm 2.3$ & $4.1 \pm 0.5$ & $4.3 \pm 0.2$ & $5.8 \pm 0.2$ & $3.3 \pm 0.1$ & $20.1 \pm 1.7$ & $14.8 \pm 0.9$ & $9.1 \pm 0.5$ \\
\hline CP-04 & $25.5 \pm 2.7$ & $5.7 \pm 0.9$ & $5.8 \pm 0.3$ & $4.7 \pm 0.3$ & $3.9 \pm 0.3$ & $66.3 \pm 1.7$ & $20.5 \pm 2.2$ & $8.5 \pm 0.4$ \\
\hline CP-05 & $\mathrm{ND}^{3)}$ & $1.9 \pm 0.4$ & $3.7 \pm 0.2$ & $3.3 \pm 0.2$ & $\mathrm{ND}$ & $9.8 \pm 1.3$ & $21.2 \pm 2.9$ & $8.0 \pm 0.4$ \\
\hline CP-06 & $\mathrm{ND}$ & $4.4 \pm 0.3$ & $8.5 \pm 0.6$ & $8.7 \pm 0.7$ & $5.3 \pm 0.2$ & $116.8 \pm 14.6$ & $27.1 \pm 2.9$ & $12.3 \pm 0.7$ \\
\hline CP-07 & $26.5 \pm 0.5$ & $8.9 \pm 0.6$ & $6.8 \pm 0.2$ & $5.2 \pm 0.2$ & $2.6 \pm 2.3$ & $24.2 \pm 5.5$ & $20.4 \pm 0.7$ & $10.0 \pm 0.2$ \\
\hline CP-08 & $22.3 \pm 1.2$ & $4.9 \pm 0.3$ & $5.3 \pm 0.2$ & $4.8 \pm 0.2$ & $\mathrm{ND}$ & $8.7 \pm 0.7$ & $18.5 \pm 1.0$ & $10.5 \pm 0.5$ \\
\hline СР-09 & $25.5 \pm 5.8$ & $6.6 \pm 1.3$ & $6.3 \pm 0.6$ & $5.0 \pm 0.1$ & $\mathrm{ND}$ & $22.1 \pm 4.7$ & $17.8 \pm 2.8$ & $9.7 \pm 0.6$ \\
\hline CP-10 & $\mathrm{ND}$ & $2.7 \pm 0.1$ & $6.9 \pm 0.5$ & $5.4 \pm 0.2$ & $\mathrm{ND}$ & $37.5 \pm 0.6$ & $10.7 \pm 0.9$ & $9.2 \pm 0.2$ \\
\hline CP-11 & $21.8 \pm 1.2$ & $7.3 \pm 0.5$ & $6.1 \pm 0.2$ & $4.1 \pm 0.1$ & $\mathrm{ND}$ & $29.7 \pm 2.8$ & $16.8 \pm 1.6$ & $9.1 \pm 0.1$ \\
\hline CP-12 & $89.7 \pm 1.4$ & $9.3 \pm 0.4$ & $7.8 \pm 0.2$ & $10.6 \pm 0.3$ & $2.4 \pm 0.1$ & $13.0 \pm 0.5$ & $36.3 \pm 2.2$ & $10.4 \pm 0.2$ \\
\hline CP-13 & $81.2 \pm 3.3$ & $12.9 \pm 0.6$ & $6.0 \pm 0.2$ & $5.5 \pm 0.1$ & $2.2 \pm 0.1$ & $14.6 \pm 0.1$ & $43.8 \pm 2.8$ & $9.8 \pm 1.0$ \\
\hline CP-14 & $\mathrm{ND}$ & ND & $5.8 \pm 0.0$ & $4.9 \pm 0.1$ & $22.3 \pm 3.6$ & $71.9 \pm 7.9$ & $25.1 \pm 1.4$ & $10.4 \pm 0.1$ \\
\hline CP-15 & $34.6 \pm 2.6$ & $9.1 \pm 1.0$ & $4.2 \pm 0.2$ & $5.1 \pm 0.4$ & $0.7 \pm 1.3$ & $40.6 \pm 9.2$ & $35.0 \pm 4.3$ & $12.2 \pm 0.9$ \\
\hline CP-16 & $11.8 \pm 0.8$ & $5.6 \pm 0.6$ & $7.0 \pm 0.5$ & $3.7 \pm 0.2$ & $1.1 \pm 0.1$ & $274.5 \pm 38.9$ & $35.3 \pm 3.5$ & $10.1 \pm 0.5$ \\
\hline CP-17 & $9.3 \pm 0.5$ & $2.5 \pm 0.2$ & $7.7 \pm 0.2$ & $4.0 \pm 0.1$ & $1.1 \pm 0.0$ & $45.1 \pm 0.7$ & $53.0 \pm 2.2$ & $11.3 \pm 0.9$ \\
\hline CP-18 & $27.9 \pm 0.3$ & $14.7 \pm 2.1$ & $7.1 \pm 0.6$ & $4.7 \pm 0.5$ & $\mathrm{ND}$ & $58.5 \pm 7.5$ & $46.0 \pm 3.1$ & $12.0 \pm 1.2$ \\
\hline CP-19 & $32.4 \pm 1.7$ & $46.2 \pm 2.6$ & $6.1 \pm 0.1$ & $5.4 \pm 0.1$ & $5.0 \pm 0.3$ & $443.4 \pm 43.5$ & $21.9 \pm 1.2$ & $\mathrm{ND}$ \\
\hline CP-20 & $34.7 \pm 2.7$ & $6.9 \pm 0.4$ & $6.0 \pm 0.6$ & $4.5 \pm 0.3$ & ND & $22.7 \pm 6.6$ & $52.1 \pm 6.3$ & $12.6 \pm 0.9$ \\
\hline CP-21 & $\mathrm{ND}$ & $\mathrm{ND}$ & $7.2 \pm 0.3$ & $4.5 \pm 0.2$ & $11.3 \pm 0.6$ & $16.4 \pm 1.3$ & $36.9 \pm 1.2$ & $10.2 \pm 0.6$ \\
\hline CP-22 & $85.5 \pm 13.0$ & $9.6 \pm 1.6$ & $43.7 \pm 5.4$ & $4.0 \pm 0.3$ & $\mathrm{ND}$ & $137.8 \pm 17.4$ & $44.9 \pm 5.3$ & $11.5 \pm 0.7$ \\
\hline CP-23 & $54.2 \pm 1.8$ & $3.2 \pm 0.5$ & $6.0 \pm 0.2$ & $10.0 \pm 0.8$ & $1.2 \pm 2.1$ & $22.5 \pm 1.2$ & $45.4 \pm 3.9$ & $10.1 \pm 0.5$ \\
\hline CP-24 & $55.0 \pm 2.6$ & $17.9 \pm 3.9$ & $7.1 \pm 0.1$ & $5.8 \pm 0.3$ & $5.0 \pm 0.4$ & $336.3 \pm 39.1$ & $27.5 \pm 0.9$ & $10.6 \pm 0.1$ \\
\hline CP-25 & $46.8 \pm 2.8$ & $4.5 \pm 0.4$ & $6.2 \pm 0.5$ & $6.8 \pm 0.5$ & ND & $8.4 \pm 0.0$ & $45.2 \pm 6.4$ & $11.3 \pm 1.4$ \\
\hline CP-26 & $84.3 \pm 4.6$ & $6.5 \pm 0.9$ & $5.3 \pm 0.3$ & $5.6 \pm 0.7$ & $0.7 \pm 1.2$ & $8.7 \pm 0.6$ & $34.1 \pm 2.3$ & $7.8 \pm 0.6$ \\
\hline CP-27 & $42.2 \pm 3.1$ & $7.0 \pm 1.5$ & $10.4 \pm 1.1$ & $7.5 \pm 1.2$ & $1.5 \pm 1.3$ & $34.1 \pm 3.2$ & $58.7 \pm 4.0$ & $9.7 \pm 0.4$ \\
\hline CP-28 & $73.3 \pm 2.3$ & $4.9 \pm 0.3$ & $18.5 \pm 1.9$ & $6.2 \pm 0.5$ & $5.6 \pm 0.6$ & $21.6 \pm 1.33$ & $43.7 \pm 5.1$ & $10.5 \pm 0.7$ \\
\hline CP-29 & $37.2 \pm 2.0$ & ND & $17.7 \pm 1.2$ & $6.7 \pm 0.4$ & $3.0 \pm 0.1$ & $8.9 \pm 0.5$ & $52.0 \pm 3.5$ & $10.4 \pm 0.8$ \\
\hline CP-30 & $97.4 \pm 3.5$ & $12.5 \pm 0.4$ & $10.6 \pm 0.4$ & $10.6 \pm 0.5$ & $2.8 \pm 0.3$ & $10.2 \pm 0.6$ & $65.6 \pm 6.4$ & $15.0 \pm 1.5$ \\
\hline CP-31 & $33.1 \pm 2.1$ & $6.0 \pm 0.3$ & $7.7 \pm 0.2$ & $5.8 \pm 0.2$ & $4.7 \pm 0.2$ & $189.9 \pm 23.6$ & $25.7 \pm 3.0$ & $11.7 \pm 0.3$ \\
\hline CP-32 & $62.9 \pm 2.2$ & $20.3 \pm 0.6$ & $15.1 \pm 0.3$ & $18.8 \pm 0.5$ & $9.7 \pm 0.5$ & $134.5 \pm 4.9$ & $57.0 \pm 1.7$ & $20.7 \pm 0.9$ \\
\hline CP-33 & $\mathrm{ND}$ & $16.3 \pm 0.8$ & $12.9 \pm 0.4$ & $15.9 \pm 0.6$ & $\mathrm{ND}$ & $179.7 \pm 13.9$ & $57.7 \pm 3.7$ & $22.5 \pm 0.6$ \\
\hline CP-34 & $164.3 \pm 22.7$ & $118.7 \pm 13.2$ & $43.6 \pm 2.2$ & $13.0 \pm 0.5$ & $9.1 \pm 0.2$ & $905.0 \pm 100.8$ & $69.1 \pm 5.4$ & $17.7 \pm 0.2$ \\
\hline CP-35 & $237.4 \pm 14.0$ & $34.5 \pm 1.6$ & $13.0 \pm 0.2$ & $12.7 \pm 0.2$ & $3.0 \pm 5.3$ & $562.1 \pm 39.3$ & $68.8 \pm 1.8$ & $19.0 \pm 2.0$ \\
\hline CP-36 & $24.8 \pm 0.7$ & $12.7 \pm 0.2$ & $36.6 \pm 2.6$ & $129.1 \pm 9.0$ & $16.3 \pm 1.1$ & $185.3 \pm 5.5$ & $46.1 \pm 0.2$ & $19.1 \pm 0.8$ \\
\hline CP-37 & $\mathrm{ND}$ & $\mathrm{ND}$ & $12.5 \pm 0.3$ & $15.3 \pm 0.5$ & $9.3 \pm 0.0$ & $56.0 \pm 3.1$ & $58.4 \pm 2.7$ & $18.8 \pm 0.8$ \\
\hline Mean & 43.8 & 11.8 & 10.6 & 10.3 & 3.8 & 113.7 & 37.6 & 11.5 \\
\hline Min. & $\mathrm{ND}$ & ND & 3.7 & 3.1 & $\mathrm{ND}$ & 8.4 & 10.7 & $\mathrm{ND}$ \\
\hline Max. & 237.4 & 118.7 & 43.7 & 129.1 & 22.3 & 905.0 & 69.1 & 22.5 \\
\hline
\end{tabular}

${ }^{1)}$ CP01-CP11, traditional market; CP12-CP37, department store (supermarket).

${ }^{2)}$ All the data were expressed as mean \pm SD $(n=3)$.

${ }^{3)} \mathrm{ND}$, not detected. 
표준기술연구소(National Institute of Standards and Technology, NIST)의 Tomato leaves, Rice flour을 이용하여 $\mathrm{Pb}, \mathrm{Cd}, \mathrm{As}$ 의 회수율을 구하였다. 그 결과 $85.3-107.1 \%$ 의 회수율을 얻을 수 있었으며, 자세한 결과는 Table 1 과 같다.

\section{측정불확도}

BAs 중 histamine 분석에서 표준용액조제, 시료전처리, 검정곡선에서 발생할 수 있는 불확도값을 요인으로 추정하 였다. 각각의 불확도인자에 대해 상대표준불확도를 구하고 포함인자 $k$ 를 이용하여 측정불확도를 산출하였다. 표준용 액 조제 시 사용된 저울은 교정 성적서상의 불확도 $95 \%$ 신뢰수준에서 $0.0004 \mathrm{~g}$ 의 불확도값으로 표준불확도는 0.0002 가 된다. 표준물질조제에 대한 합성표준불확도는 0.0154 이었다. 표준물질 희석은 저울과 부피용기가 사용되 었으며, $100 \mathrm{~mL}$ 부피플라스크의 교정성적서상의 불확도 95\% 신뢰수준에서 $0.0610 \mathrm{~mL}$ 의 불확도값으로 표준불확도 는 0.0305 이 된다. 표준용액 희석에 대한 합성표준불확도는 0.0004 이었다.

시료전처리 불확도는 각각 저울과 pipet이 사용되었으며, 각각의 상대표준불확도는 $0.0002 \mathrm{~g}, 0.007 \mathrm{~mL}, 0.007 \mathrm{~mL}$, $0.0004 \mathrm{~mL}, 0.0004 \mathrm{~mL}$ 로 합성표준불확도는 0.0007 이었다.

검정곡선의 불확도는 희석된 표준용액 $1.0 \mathrm{mg} / \mathrm{L}, 2.0$ $\mathrm{mg} / \mathrm{L}, 4.0 \mathrm{mg} / \mathrm{L}, 10 \mathrm{mg} / \mathrm{L}$ 을 3회 반복측정하여 회귀분석을 이용하여 산출하였다. 직선성의 표준불확도는 0.0382 $\mathrm{mg} / \mathrm{L}$, 자유도는 10 , 상대표준불확도는 $0.0071 \mathrm{mg} / \mathrm{L}$ 이었다.

합성상대불확도 0.017 에 측정농도 $5.37 \mathrm{mg} / \mathrm{L}$ 을 곱하여 합성표준불확도 $0.091 \mathrm{mg} / \mathrm{kg}$ 을 산출하며, 포함인자는 유효 자유도가 323(유효자유도 10 이상)이므로 신뢰수준 약 $95 \%, k=2$ 로 계산되었다. Histamine의 확장불확도는 희석배 수를 고려하여 $53.7 \mathrm{mg} / \mathrm{kg} \pm 1.82 \mathrm{mg} / \mathrm{kg}$ 으로 약 $3 \%$ 이내의 오차값을 나타내었다. 불확도 요인에 따른 기여도는 표준 물질 조제 $66.9 \%$, 시료전처리 $2.91 \%$, 검정곡선 $30.2 \%$ 로
불확도요인 중에 표준물질 조제와 검정곡선이 $90 \%$ 이상의 기여를 하고 있음을 알 수 있었다.

\section{청국장에서 바이오제닉아민 함량}

본 연구에서는 유통중인 청국장 37건에 대하여 TRP, PHE, PUT, CAD, HIS, TYR, SPD, SPM 총 8항목의 BAs을 분석하였으며 분석결과는 Table 3 과 같다. BAs의 검출된 항목중에 TYR이 평균 $113.7 \mathrm{mg} / \mathrm{kg}$ 로 다른 $\mathrm{BAs}$ 의 평균 농도에 비해 약 2.5 배에서 최대 약 30 배 정도 높은 결과를 나타내었으며, $8.4-905.0 \mathrm{mg} / \mathrm{kg}$ 의 농도범위로 시료간 농도 의 차이가 매우 크게 나타남을 알 수 있었다. Han 등(12)의 연구에서 TYR 4.2-483.1 mg/kg의 범위를 보여주어 다른 amine에 비해 높게 나타났다. 식중독 원인이 되는 것으로 밝혀진 HIS의 평균농도는 $3.8 \mathrm{mg} / \mathrm{kg}$ 으로 가장 낮은 수치를 나타냈으며, 37 건 중 10 건에서는 검출이 되지 않았다. 이는 Cho 등(18)의 연구의 $10.1 \mathrm{mg} / \mathrm{kg}$ 보다는 다소 낮은 수치였 다. 또한 ND-22.3 mg/kg의 농도범위로 Han 등(12)의 연구의 $0.2-70.3 \mathrm{mg} / \mathrm{kg}$ 에 비해 낮은 농도범위를 보여주었다. PHE $\mathrm{PUT}, \mathrm{CAD}, \mathrm{SPM}$ 는 각각 $11.8 \mathrm{mg} / \mathrm{kg}, 10.6 \mathrm{mg} / \mathrm{kg}, 10.3$ $\mathrm{mg} / \mathrm{kg}, 11.5 \mathrm{mg} / \mathrm{kg}$ 으로 비슷한 평균값을 나타내었고, Cho 등(18)의 연구의 $22.0 \mathrm{mg} / \mathrm{kg}, 26.4 \mathrm{mg} / \mathrm{kg}, 9.7 \mathrm{mg} / \mathrm{kg}, 10.7$ $\mathrm{mg} / \mathrm{kg}$ 와 비교하였을 때 PHE, PUT를 제외하고는 비슷한 평균값을 나타내었다. TRP와 SPD 또한 $43.8 \mathrm{mg} / \mathrm{kg}, 37.6$ $\mathrm{mg} / \mathrm{kg}$ 으로 비슷한 평균값을 나타내었고, Cho 등(18)의 연 구의 $69.9 \mathrm{mg} / \mathrm{kg}, 52.0 \mathrm{mg} / \mathrm{kg}$ 보다는 약간 낮은 값을 나타내 었다. 8항목의 BAs중 PUT, CAD, TYR, SPD는 37건의 시료 에서 모두 검출이 되었다. 분석대상 $\mathrm{BAs}$ 중 위해성과 관련 된 보고가 있었던 물질은 PUT, $\mathrm{CAD}, \mathrm{HIS}, \mathrm{TYR}, \mathrm{PHE}$ 이며 나머지 이 외의 항목들은 위해성과 관련된 결과가 보고된 바가 없다(19).

현재까지 우리나라를 비롯하여 외국의 경우 BAs에 대한 총체적인 기준이나 규격을 정하여 관리하는 국가는 없다.

Table 4. Contents of mineral elements in Cheonggukjang

\begin{tabular}{|c|c|c|c|c|c|c|c|}
\hline \multirow{2}{*}{ Test No. } & \multicolumn{6}{|c|}{ Mineral elements concentration (\%) } & \multirow{2}{*}{$\begin{array}{c}\text { Mineral ratio } \\
\mathrm{Na} / \mathrm{K}\end{array}$} \\
\hline & $\mathrm{Na}$ & $\mathrm{K}$ & $\mathrm{Ca}$ & $\mathrm{P}$ & $\mathrm{Mg}$ & $S$ & \\
\hline CP-01 & $0.47 \pm 0.02^{1)}$ & $0.63 \pm 0.03$ & $0.14 \pm 0.01$ & $0.35 \pm 0.03$ & $0.13 \pm 0.03$ & $0.23 \pm 0.01$ & 0.76 \\
\hline $\mathrm{CP}-02$ & $0.99 \pm 0.05$ & $0.51 \pm 0.02$ & $0.13 \pm 0.01$ & $0.34 \pm 0.01$ & $0.11 \pm 0.002$ & $0.19 \pm 0.02$ & 1.93 \\
\hline CP-09 & $0.34 \pm 0.01$ & $0.61 \pm 0.01$ & $0.17 \pm 0.01$ & $0.33 \pm 0.03$ & $0.15 \pm 0.01$ & $0.18 \pm 0.002$ & 0.56 \\
\hline CP-12 & $0.53 \pm 0.04$ & $0.59 \pm 0.04$ & $0.17 \pm 0.01$ & $0.29 \pm 0.02$ & $0.12 \pm 0.01$ & $0.18 \pm 0.004$ & 0.9 \\
\hline CP-21 & $2.03 \pm 0.24$ & $0.43 \pm 0.05$ & $0.11 \pm 0.01$ & $0.19 \pm 0.03$ & $0.06 \pm 0.01$ & $0.10 \pm 0.004$ & 4.76 \\
\hline CP-25 & $1.19 \pm 0.03$ & $0.51 \pm 0.02$ & $0.11 \pm 0.001$ & $0.28 \pm 0.01$ & $0.09 \pm 0.001$ & $0.15 \pm 0.01$ & 2.32 \\
\hline Mean & 0.93 & 0.55 & 0.14 & 0.3 & 0.11 & 0.17 & .2) \\
\hline Min. & 0.34 & 0.43 & 0.11 & 0.19 & 0.06 & 0.1 & - \\
\hline Max. & 2.03 & 0.63 & 0.17 & 0.35 & 0.15 & 0.23 & - \\
\hline
\end{tabular}

${ }^{1)}$ All the data were expressed as mean $\pm \mathrm{SD}(\mathrm{n}=3)$.

2), no value. 
Table 5. Contents of minor elements in Cheonggukjang

\begin{tabular}{|c|c|c|c|c|c|c|c|c|c|c|c|c|}
\hline \multirow{2}{*}{ Test No. } & \multicolumn{8}{|c|}{ Minor elements concentration $(\mathrm{mg} / \mathrm{kg})$} & \multicolumn{4}{|c|}{ Heavy metals concentration $(\mathrm{mg} / \mathrm{kg})$} \\
\hline & $\mathrm{Fe}$ & $\mathrm{Mn}$ & $\mathrm{Zn}$ & $\mathrm{Cu}$ & $\mathrm{Sr}$ & Mo & $\mathrm{Ba}$ & $\mathrm{Se}$ & $\mathrm{Pb}$ & $\mathrm{Cd}$ & As & $\mathrm{Hg}$ \\
\hline CP-01 & $33.8 \pm 3.12^{1)}$ & $17.4 \pm 3.90$ & $23.1 \pm 3.99$ & $4.51 \pm 0.73$ & $3.88 \pm 0.57$ & $1.25 \pm 0.02$ & $3.12 \pm 1.01$ & $0.036 \pm 0.001$ & $\mathrm{ND}^{2)}$ & $0.015 \pm 0.003$ & ND & ND \\
\hline CP-02 & $32.5 \pm 4.85$ & $12.9 \pm 0.44$ & $21.1 \pm 0.32$ & $2.60 \pm 0.19$ & $2.84 \pm 0.70$ & $2.21 \pm 0.19$ & $1.04 \pm 0.08$ & $0.033 \pm 0.005$ & ND & $0.012 \pm 0.001$ & ND & ND \\
\hline CP-09 & $36.7 \pm 7.51$ & $13.8 \pm 0.31$ & $18.1 \pm 0.64$ & $4.96 \pm 0.05$ & $3.67 \pm 0.54$ & $1.42 \pm 0.12$ & $0.47 \pm 0.07$ & $0.067 \pm 0.020$ & $\mathrm{ND}$ & $0.012 \pm 0.003$ & $0.015 \pm 0.006$ & ND \\
\hline $\mathrm{CP}-12$ & $27.7 \pm 1.03$ & $14.4 \pm 0.74$ & $16.8 \pm 0.50$ & $4.10 \pm 0.75$ & $3.62 \pm 0.24$ & $1.70 \pm 0.17$ & $4.76 \pm 0.35$ & $0.12 \pm 0.01$ & $\mathrm{ND}$ & $0.015 \pm 0.0003$ & ND & ND \\
\hline CP-21 & $19.2 \pm 2.59$ & $8.05 \pm 1.42$ & $9.37 \pm 0.79$ & $1.75 \pm 0.04$ & $2.23 \pm 0.30$ & $0.94 \pm 0.001$ & $1.70 \pm 0.36$ & $0.12 \pm 0.016$ & $\mathrm{ND}$ & $0.011 \pm 0.0002$ & $0.049 \pm 0.001$ & ND \\
\hline CP-25 & $27.8 \pm 2.05$ & $14.0 \pm 0.47$ & $16.9 \pm 0.80$ & $2.72 \pm 0.17$ & $3.02 \pm 0.20$ & $0.89 \pm 0.14$ & $1.61 \pm 0.13$ & $0.049 \pm 0.01$ & $\mathrm{ND}$ & $0.016 \pm 0.001$ & $\mathrm{ND}$ & $\mathrm{ND}$ \\
\hline Mean & 29.6 & 13.4 & 17.6 & 3.44 & 3.21 & 1.4 & 2.12 & 0.071 & $\mathrm{ND}$ & 0.014 & 0.011 & ND \\
\hline Min. & 19.2 & 8.05 & 9.37 & 1.75 & 2.23 & 0.89 & 0.47 & 0.12 & -3) & 0.016 & - & - \\
\hline Max. & 36.7 & 17.4 & 23.1 & 4.96 & 3.88 & 2.21 & 4.76 & 0.033 & - & 0.011 & 0.049 & - \\
\hline
\end{tabular}

${ }^{1)}$ All the data were expressed as mean \pm SD $(n=3)$.

${ }^{2} \mathrm{ND}$, not detected.

3), no value.

우리나라의 경우 HIS의 냉동 및 염장어류, 통조림 등 수산 물에 대하여 $200 \mathrm{mg} / \mathrm{kg}$ 로 규격을 설정하고 있으며, 미국이 나 EU의 경우 자국 내 히스타민에 대한 어류 및 가공어육에 대해서만 권장규격이 있는 실정이다. 추후 바이오제닉아민 에 대한 유해성 연구가 진행이 되면 발효식품 내 바이오제 닉아민에 대한 규제로 인해 청국장의 제조 유해물질의 저감 화 기술이 필요하다. 현재 유통되고 있는 청국장은 $\mathrm{BAs}$ 생성에 관여하고 있는 미생물 Enterobacteriaceae, Clostridium spp, Lactobacillus spp. 등이 있으며, 식품의 미 생물의 분포 및 제조발효 시간 등에 따른 공정의 차이에 따라 유해물질의 함량은 다르게 나타는 것으로 보인다 $(13,20)$. 유통되는 청국장의 BAs의 함량 결과에 따른 시료 의 상관관계를 파악하기 어려웠으며, 앞으로 안전한 청국 장을 제공하기 위해 청국장 제조공정의 표준화 및 규격설정 이 필요하다고 생각된다. 추후 시중 유통되는 청국장의 제 조공정별 검사를 실시하여 지속적인 안전관리가 필요할 것이다.

\section{청국장에서 무기원소 함량}

우리나라에서 유통 중인 청국장의 무기성분 18 성분 중 주요무기원소 $(\mathrm{Na}, \mathrm{K}, \mathrm{Ca}, \mathrm{P}, \mathrm{Mg}, \mathrm{S})$ 와 미량무기원소 $(\mathrm{Fe}, \mathrm{Mn}$, $\mathrm{Zn}, \mathrm{Cu}, \mathrm{Sr}, \mathrm{Mo}, \mathrm{Ba}, \mathrm{Se})$ 및 유해중금속 $(\mathrm{Pb}, \mathrm{Cd}, \mathrm{As}, \mathrm{Hg})$ 함량을 분석한 결과는 Table 4 와 같다. 주요무기원소 중 $\mathrm{Na}$ 의 평균함량이 가장 높았으며, 평균 $0.93 \%, 0.34-2.03 \%$ 의 농도 범위로 최대 6 배 정도 차이가 났다. $\mathrm{Na}$ 함량은 청국장 자체의 농도에 따른 차이보다 제조 과정에서의 첨가물 등에 의해 기인된 현상이라고 생각된다. $\mathrm{K}$ 는 평균 $0.55 \%$, 0.43-0.63\%의 농도 범위를 나타냈으며, 청국장 종류에 상관 없이 비슷한 값을 나타내었다. $\mathrm{Na}$ 은 섭취량이 높을수록 고혈압 등 심혈관 질환의 발생률을 높이는 것으로 알려져 있다(21). 한편 $\mathrm{K}$ 은 $\mathrm{Na}$ 의 과잉 섭취로 유발되는 고혈압에
대해 방어 작용을 한다고 알려져 있다. $\mathrm{Na} / \mathrm{K}$ ratio을 1 에 가깝게 낮추면 고혈압을 개선시키는 효과가 있으며, $\mathrm{Na}$ 과 $\mathrm{K}$ 각각의 섭취보다 $\mathrm{Na} / \mathrm{K}$ 의 비율이 고혈압에 대한 연관이 더 크다고 보고되고 있다(22). 본 연구에서 시판 청국장의 $\mathrm{Na} / \mathrm{K}$ ratio를 분석한 결과, 0.56-4.76 수준으로 나타났다.

$\mathrm{Na}$ 과 $\mathrm{K}$ 외에 주요무기원소 중에서 $\mathrm{Ca}, \mathrm{P}, \mathrm{Mg}, \mathrm{S}$ 와 주요미 량원소 중에서 $\mathrm{Fe}, \mathrm{Mn}, \mathrm{Zn}, \mathrm{Cu}, \mathrm{Sr}$ 의 경우에는 시료 종류에 상관없이 비슷한 수치를 나타내었다(Table 4, 5). 청국장과 유사한 발효식품 중 하나인 된장의 모니터링 결과 $\mathrm{Zn} 16.7$ $\mathrm{mg} / \mathrm{kg}, \mathrm{Cu} 5.09 \mathrm{mg} / \mathrm{kg}, \mathrm{Mn} 15.9 \mathrm{mg} / \mathrm{kg}(23)$ 로 비슷한 수치를 나타냈으며, 또 다른 보고서에서도 $\mathrm{Zn} 19.4 \mathrm{mg} / \mathrm{kg}, \mathrm{Cu} 5.5$ $\mathrm{mg} / \mathrm{kg}(24)$ 로 나타났다. 다량 무기질 이외의 미량 무기질의 경우에는 제조공정보다는 생콩 자체로 인해 나타나는 결과 로 보인다.

유해중금속인 $\mathrm{Pb}, \mathrm{Cd}, \mathrm{As}, \mathrm{Hg}$ 의 경우에는 정량한계 이하 로 검출이 되지 않거나 0.011-0.049 mg/kg 수준으로 나타났 다. 모니터링 결과 국내 보고서에 나타난 된장의 함량과 비교하였을 때 큰 차이가 없었으며, 유해중금속은 검출이 되지 않거나 검출이 되더라도 $0.1 \mathrm{mg} / \mathrm{kg}$ 이하로 나타나는 것을 알 수 있었다. 현재 장류에 대한 중금속의 기준치는 없는 상태이며, 다른 나라에도 없는 실정이다.

\section{요 약}

본 연구는 마트와 시장에서 유통되고 있는 청국장 37건 의 BAs 8 성분과 무기성분 18 성분에 대한 함량을 조사하였 다. $\mathrm{BAs}$ 은 $\mathrm{HPLC}$ 를 이용하여 분석하였고, 무기성분은 ICP-AES와 ICP-MS를 이용하여 분석을 진행하였다. BAs 8 성분 중 TYR함량이 $113.7 \mathrm{mg} / \mathrm{kg}$ 으로 가장 높게 나타났으 며, 시료에 따라 농도차이가 크게 나타났다. 다음으로는 
$\mathrm{TRP}$ 와 $\mathrm{SPD}$ 의 함량이 높았으며, $\mathrm{PHE}, \mathrm{PUT}, \mathrm{CAD}, \mathrm{SPM}$ 은 비슷한 수준으로 검출이 되었다. PUT, CAD, TYR, SPD는 모든 시료에서 검출이 되었다. HIS는 평균농도 $3.8 \mathrm{mg} / \mathrm{kg}$ 으 로 제일 낮은 결과를 보였다. 무기성분 중 $\mathrm{Na}$ 의 평균농도 $0.93 \%$ 로 가장 높았으며, 0.34-2.03\%로 시료에 따라 함량의 차이가 크게 나타났으며, $\mathrm{K}, \mathrm{Ca}, \mathrm{P}, \mathrm{Mg}, \mathrm{S}$ 은 0.1-0.5\% 수준으 로 나타났다. 그 외의 성분들은 미량이었으며, 유해 중금속 또한 아주 극미량이거나 검출이 되지 않았다. BAs 성분들 은 발효과정 중 생성되는 유해물질로 미네랄이나 미량 무기 원소와의 연관성은 따로 없는 것으로 보인다. BAs는 청국 장 제조 시 미생물 균주의 발효 과정 중 생성되는 반면, 미네랄이나 기타 무기원소들은 발효 과정 중에 기인하는 것보다 원재료인 콩의 무기원소 함량에 의해 결정되기 때문 이다. BAs와 특정 무기 성분과의 유기성을 살펴보기 위해 서는 더 많은 연구와 모니터링이 필요할 것으로 보인다. 본 연구 결과청국장마다 BAs의 농도가 상이하게 나타난 것을 알 수 있었다. 이는 청국장의 규격화된 제조공정이 없고, 구체적인 규격이나 관리가 없기 때문으로 보인다. 독성물질인 BAs나 유해중금속의 경우 지속적인 모니터링 을 통해 안전관리가 필요할 것으로 보이며, 또한 이에 맞는 정확한 기준이 만들어져야 할 것이다.

\section{감사의 글}

이 논문은 2018년도 정부(과학기술정보통신부)의 재원 으로 한국연구재단-전통문화융합연구사업의 지원을 받아 수행된 연구임(No. 2016M3C1B5907267).

\section{References}

1. Wang YS, Roh KS (2009) Biochemical properties of seed lectin from Korean soybean cultivars developed for soy source. KSBB J, 24, 170-176

2. Lee BY, Kim DM, Kin KH (1991) Studies on the change in rheological properties of Chungkook-jang. Korean J Food Sci Technol, 23, 478-484

3. Kang SJ, Kim SS, Chung HY (2014) Comparison of physicochemical characteristics and consumer perception of Cheongkukjang. J Korean Soc Food Sci Nurt, 43, 1104-1111

4. Chang KA (2007) Analysis of heavy metal contents of traditional foods in Honam region. MS Thesis, Chosun University, Korea, p 1-2

5. Kim JH, Ahn HJ, Yook HS, Park HJ, Byun MW (2001) Biogenic amines content in commercial Korean traditional fermented soybean paste. Korean J Food Sci Technol, 33, 682-685

6. Choi UK, Ji WD, Chung YG (1998) Characteristic of Chunggugjang produced by Bacillus subtilis DC-2. J Korean Soc Food Sci Nurt, 27, 846-851

7. Suh JS, Lee SG, Ryu MK (1982) Effect of Bacillus strains on the Chungkook-jang processing. (I) Changes of the components and enzyme activities during the storage of Chungkook-jang. Korean J Food Sci Technol, 309-314

8. Choi UK, Son DH, Ji WD, Im MH, Choi JD, Chung YG (1998) Changes of taste components and palatability during Chunggugjang fermentation by Bacillus subtilis DC-2. J Korean Soc Food Sci Nurt, 27, 840-845

9. Seok YR, Kim YH, Kim S, Woo HS, Kim TW, Lee SH, Choi C (1994) Change of protein and amino acid composition during Chungkook-jang fermentation using Bacillus Licheniformis CN-115. J Appl Biol Chem, 37, 65-71

10. Kim DH, Lim DW, Bai S, Chun SB (1997) Fermentation characteristics of whole soybean meju model system inoculated with 4 Bacillus strains. Korean J Food Sci Technol, 29, 1006-1015

11. Youn KC, Kim DH, Kim JO, Park BJ, Yook HS, Cho JM, Byun MW (2002) Quality characteristics of the Chungkook-jang fermented by the mixed culture of Bacillus natto and B. licheniformis. J Korean Soc Food Sci Nutr, 31, 204-210

12. Han GH, Cho TY, Yoo MS, Kim CS, Kim JM, Kim HA, Kim MO, Kim SC, Lee SA, Ko YS, Kim SH, Kim DB (2007) Biogenic amines formation and content in fermented soybean paste (Cheonggukjang). Korean J Food Sci Technol, 39, 541-545

13. Shalaby AR (1996) Significance of biogenic amines to food safety and human health. Food Res Int, 29, 675-690

14. Garcia-Garcia P, Brenes-Balurna M, Hornero-Mendez D, Garcia-Borrego, A, Garrido-Fernandez A (2000) Content of biogenic amines in table olives. J Food Prot, 63, 111-116

15. The Pharmaceutical Society of Japan (2005) Methods of Analysis in Health Science, Tokyo, Japan, 180-182

16. Ministry of Food and Drug Safety. http://www. foodsafetykorea. go.kr/foodcode/01_02.jsp?idx=263 (accessed December 2016)

17. ISO, BIPM, IEC, IFCC, IUPAC, IUPAP, OIML (1995) Evaluation of measurement data-Guide to the expression of uncertainty in measurement. JCGM, Geneva, Switzerland 18. Cho TY, Han GH, Bahn KN, Son YW, Jang MR, Lee 
CH, Kim SH, Kim DB, Kim SB (2006) Evaluation of biogenic amines in Korean commercial fermented foods. Korean J Food Sci Technol, 38, 730-737

19. Kim JH (2013) Research on safety improvement of fermented agricultural product. Final Report of RDA, RDA PJ007425

20. Kim JH, Park HJ, Kim MJ, Ahn HJ, Byun MW (2003) Survey of biogenic amine contents in commercial soy sauce. Korean J Food Sci Technol, 35, 325-328

21. Cheon SH, Lee SI, Hwnag IM, Seo HY (2017) Quality characteristics of commercial kimchi paste. Korean J Food Cook Sci, 33, 9-19
22. Park YH, Chung SJ (2016) A comparison of sources of sodium and potassium intake by gender, age and regions in Koreans: Korea National Health and Nutrition Examination Survey (KNHANES) 2010-2012. Korean J Community Nutr, 21, 558-573

23. Choi DW (2006) Survey for heavy metal contents in frequently consumed food. Final Report of MFDS, MFDS 06041

24. Yoon WJ, Lee SW, Moon HK, Moon JN, Kim BG, Kim BJ, Kim GY (2011) Quality characteristics of traditional soybean paste (Doenjang) manufactured with mixed beans. J East Asian Soc Dietary Life, 21, 375-384 